\title{
Efficacy of Pregabalin in the Treatment of Radicular Pain: Results of a Controlled Trial
}

\author{
Khalid M. Malik ${ }^{1,{ }^{*}}$; Ariana M. Nelson ${ }^{1}$; Michael J. Avram ${ }^{1}$; Sabrina Lee Robak ${ }^{1}$; Honorio T. \\ Benzon $^{1}$ \\ ${ }^{1}$ Department of Anesthesiology, Northwestern University, Chicago IL, USA \\ *Corresponding author: Khalid Mehmood Malik, Department of Anesthesiology, Northwestern University, Chicago IL, USA. Tel: +1-3124852938, Fax:+1-3126957605, E-mail: kmalikmd@yahoo.com \\ Received: February 24, 2015; Accepted: March 29, 2015
}

\begin{abstract}
Background: Pregabalin is commonly used to treat patients with various neuropathic pain syndromes.
Objectives: The purpose of the present study was to evaluate the efficacy of pregabalin in patients with lumbar or cervical radicular pain. Patients and Methods: A prospective, randomized, double-blind trial was conducted in 39 patients with lumbar and cervical radicular pain, who received 3 weeks of either pregabalin $(n=10)$ or placebo $(n=9)$ treatment. Baseline pain and disability were evaluated before the treatment and were re-evaluated, along with overall patient satisfaction, after the 3 weeks of treatment.

Results: Data on 19 of the 39 patients recruited were available for analysis. No statistically significant differences in the pain, disability, and patient satisfaction scores were found between the groups. When the individual patient scores were assessed, the placebo treatment was found to be efficacious in 4 of the 9 patients and pregabalin was effective in 2 of the 10 patients, but the difference was not statistically significant $(\mathrm{P}=0.350)$.

Conclusions: The present data do not suggest that pregabalin is more efficacious than placebo in the treatment of lumbar and cervical radicular pain. However, the small sample size of this study may have affected the ability to detect such a difference.
\end{abstract}

Keywords: Pain; Pregabalin; Analgesics; Analgesics, Non-Narcotic; Intervertebral Disc Displacement

\section{Background}

Pregabalin is classified as an anticonvulsant drug. However, its use for the treatment of several neuropathic pain syndromes is prevalent, and it is approved by the Food and Drug Administration (FDA) for the treatment of diabetic neuropathy, post-herpetic neuralgia, and fibromyalgia $(1,2)$. Neuropathic pain is a well-recognized clinical entity. It is defined as pain caused by the lesion or dysfunction of the peripheral or central nervous system (3), and it can be diagnosed by wellestablished clinical criteria $(4,5)$. Radicular pain (RP) is the pain and paresthesia experienced in dermatomal distribution (6) from the lesion or dysfunction of the dorsal root ganglia (7). Mechanical compression with or without the local inflammation of the dorsal root ganglia modulates the surface sodium $\left(\mathrm{Na}^{+}\right)$, potassium $\left(\mathrm{K}^{+}\right)$, and calcium $\left(\mathrm{Ca}^{++}\right)$receptors and leads to spontaneous and ectopic neuronal firing (8). The antidromic spread of these impulses along the peripheral nerves is perceived as pain and paresthesia (8), indicating the neuropathic origin of RP. The common etiologies of RP include herniated discs, spinal stenosis, and scarring in the epidural space after spinal surgery (9).
Pregabalin is an analog of inhibitory neurotransmitter gamma-aminobutyric acid (GABA), though it does not bind directly to either $\mathrm{GABA}_{\mathrm{A}}$ or $\mathrm{GABA}_{\mathrm{B}}$ receptors. Pregabalin does, however, bind to the alpha-2-delta $\left(\alpha_{2} \delta\right)$ subunit of voltage-gated presynaptic $\mathrm{Ca}^{++}$channels and reduce the $\mathrm{Ca}^{++}$ion influx (2). Through this mechanism, pregabalin suppresses ectopic neuronal impulses and could, as a result, be efficacious in patients with lumbar and cervical RP.

Low back and neck pain are common and are a significant source of disability and morbidity in industrialized nations. The prevalence and lifetime incidence of low back and neck pain syndromes is as high as $30 \%$ and $100 \%$, respectively $(9,10)$. The annual health care costs related to these pain syndromes amount to billions of dollars in the United States alone (10). Nearly $40 \%$ of the patients with low back and neck pain syndromes have RP (11) and, therefore, may be responsive to treatment with pregabalin. The off-label use of pregabalin for the various pain syndromes in general, and for RP in particular, is ubiquitous. However, minimal support for this practice exists in the literature and its cost is perhaps exorbitant. 


\section{Objectives}

We conducted this randomized, double-blind, placebocontrolled trial to determine the efficacy of pregabalin in patients with lumbar and cervical RP in order to validate or refute this popular practice.

\section{Patients and Methods}

All patients between the ages of 18 to 65 years presenting to Northwestern university hospital pain medicine center with the diagnosis of chronic cervical or lumbar RP were eligible for this study (Box 1). To maximize the treatment effect and maintain a homogenous study population, only patients with RP of more than 3 months' duration from herniated disc, spinal stenosis, or failed back surgery syndrome were considered eligible for the study. As most patients presented to our facility for epidural steroid injections, only patients who had persistent pain despite a series of epidural steroid injections within the previous 6 months were recruited. Patients with a history of depression, peripheral neuropathy, addiction, narcotic drug abuse, neurological deficits, workmen's compensation and disability issues, and those with prior gabapentin or pregabalin use were excluded. Patients using strong narcotics such as morphine, hydromorphone, oxycodone, oxymorphone, and transdermal fentanyl were also excluded. Also excluded were patients with any of a host of labeled contraindications to pregabalin use such as known hypersensitivity, history of angioedema, congestive heart failure, and conduction disorder.

The study was approved by the Northwestern university (Chicago, Illinois) institutional review board and was registered with clinicaltrials.gov (NCT-00908375). The study participants were randomly assigned to one of the two study groups. The participants in one study group received pregabalin, while those in the other received placebo. Both pregabalin and placebo were in capsule form and looked identical. (Only 75-mg pregabalin capsules were used.) Patients in the pregabalin group received one pregabalin capsule twice a day for the first week $(150 \mathrm{mg} /$ day) and two pregabalin capsules twice a day $(300 \mathrm{mg}$ day) for the subsequent 2 weeks. Patients in the placebo group received the placebo pill in an identical manner. The overall duration of the treatment was 3 weeks.

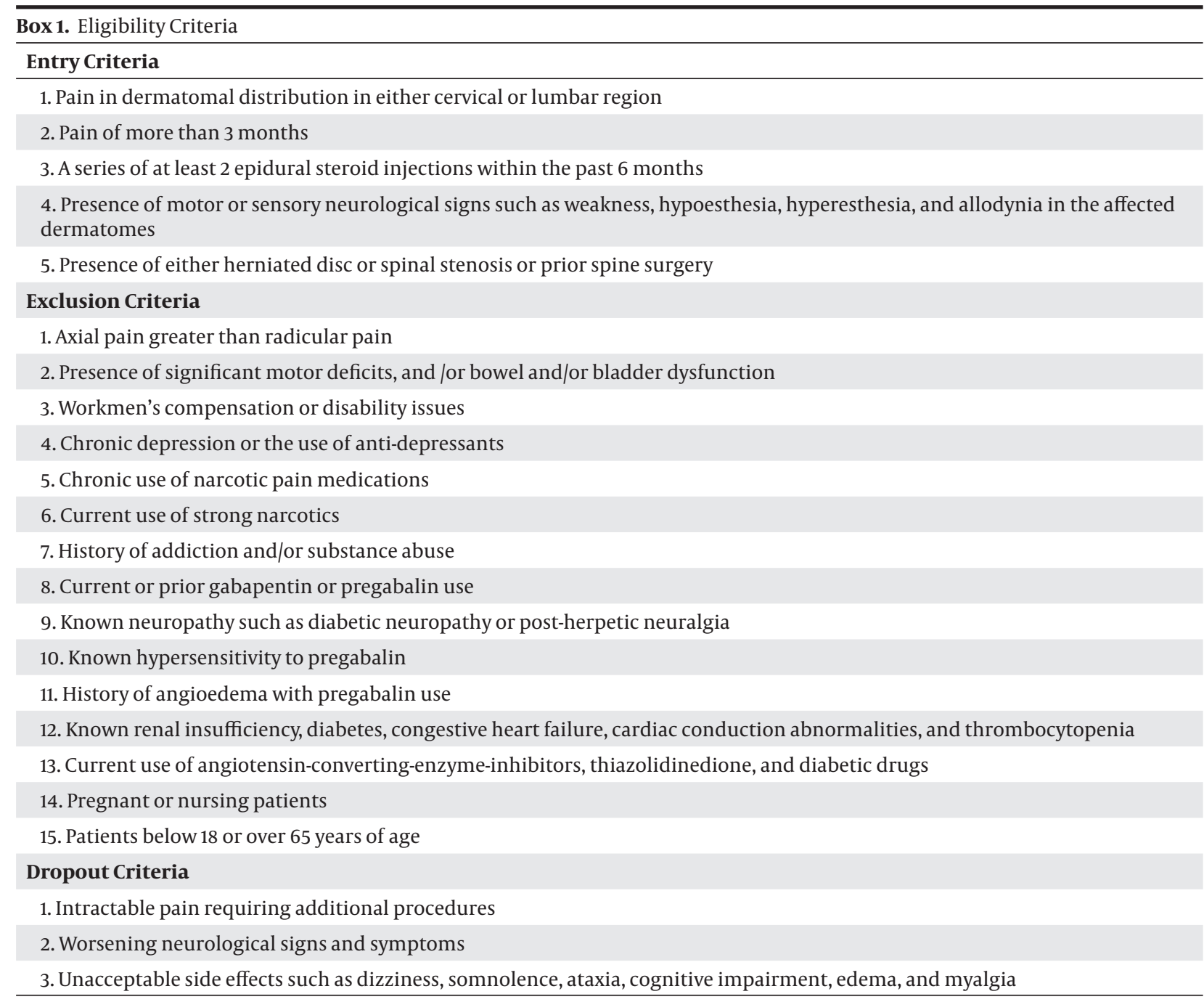


The pregabalin and placebo capsules were prepared by the pharmacy staff, all of whom were otherwise uninvolved in patient care. Randomization was computergenerated, and the study coordinators and participants were blinded to the treatment group. The pharmacy staff dispensed the assigned treatment with the label "study drug". The double-blinded nature of the study was maintained until the last patient was recruited. Informed consent was obtained from the eligible patients after the off-label use of pregabalin and its possible adverse effects as well as the likelihood of placebo administration was fully explained to the potential study participants. The study participants completed the baseline study questionnaires after providing informed consent. After completing the 3-week drug trial, the study participants were evaluated by a follow-up clinic visit and completed a second set of study questionnaires.

Response to treatment was evaluated in three outcome domains: pain; disability; and patient satisfaction. Pain relief, the primary outcome measure, was evaluated using the Numeric Rating Pain Scale (NRS). The secondary outcomes of change in disability level and patient satisfaction with treatment were evaluated by using the Oswestry disability index (ODI) and the patient's global impression of change scale (PGIC), respectively. The NRS is an 11-point verbal rating pain scale, ranging from 0 to 10 , with 0 signifying no pain at all and 10 signifying the worst pain imaginable (12). The ODI measures the subject's functional status or disability and contains 10 questions with 0 - 5 Likert scale responses (13). The score obtained is converted to percent disability (total score $/ 50 \times 100$ ): a score of $0 \%$ to $20 \%$ indicates minimal disability (a patient can cope with most living activities); $21 \%$ to $40 \%$ indicates moderate disability (a patient has difficulty sitting, lifting, and standing and, therefore, has limitations with travel, social life, and some vocational activities); $41 \%$ to $60 \%$ indicates severe disability (most activities of daily living are affected); $61 \%$ to $80 \%$ denotes crippled patients (this level of disability impinges on all aspects of the patient's life); and 81 to $100 \%$ indicates a bed-bound patient. The PGIC indicates the patient's overall impression of change over the course of the treatment and is comprised of the Likert scale ranging from 1 to 7 , with 1 indicating very much improved, 2 much improved, 3 minimally improved, 4 no change, 5 minimally worse, 6 much worse, and 7 very much worse (14). Based on the previously validated criteria, a 2-point decrease in the NRS score, $10 \%$ decrease in the ODI score, and a score of $1,2,5$, and 6 on the PGIC were considered significant clinical change (12-14).

The sample size was determined based on the primary outcome variable, the NRS pain score. Based on the results of the study by Siddall et al. (15), group sample sizes of 19 and 19 achieve $82 \%$ power to detect a difference of 2.000 between the null hypothesis that both placebo and pregabalin group means are 6.500 and the alternative hypothesis that the mean of the pregabalin group is 4.500 , with estimated group standard deviations of 2.100 and 2.100 and with a significance level (alpha) of 0.05 using a two-sided two-sample ttest. The data are reported as mean and standard deviation, median and range, or number and percent. Baseline pain and disability as well as pain, disability, and patient satisfaction at 3 weeks were compared between the groups using the Mann-Whitney U Test. Baseline pain and disability were compared within the groups with pain and disability at 3 weeks using the Wilcoxon signed-ranks test. Median differences and the $99 \%$ confidence intervals for the differences were determined. The criterion for the rejection of the null hypothesis was a two-tailed $\mathrm{P}<0.05$, which was adjusted for multiple applications of tests to the same data using the Bonferroni correction.

\section{Results}

We screened 268 patients for the study between June 18th, 2009 and August 9th, 2012 (Figure 1). Of these, 109 patients declined to participate in the study, the majority due to personal preference to avoid participating in a blinded trial. There were 120 patients who did not meet the study eligibility criteria and were excluded from the study. The most common reasons for exclusion were current or prior pregabalin/gabapentin use and current use of strong opioids. Thirty-nine patients were recruited in the study: 19 patients in the placebo group and 20 in the pregabalin group. Nineteen of the 39 patients recruited returned for their follow-up appointment:10 patients in the pregabalin group and 9 in the placebo group, who were included in the final analysis. Ten patients from each group dropped out of the study. Seventeen patients did not return for the followup visit despite multiple phone calls and reminders. Three patients withdrew from the study due to adverse effects: 2 in the placebo group, due to rash and palpitations, and 1 in the pregabalin group, due to the worsening of preexisting migraine headaches.

The baseline characteristics of the study participants are summarized in Table 1 . The groups of patients randomly assigned to receive placebo or pregabalin that completed the trial and those who withdrew from the trial were similar with respect to age, sex, source of pain (lumbar or cervical), prior surgery, and the baseline NRS and ODI scores.

The treatment responses of the placebo and pregabalin groups measured in the domains of pain, disability, and satisfaction with treatment are presented in Table 2 . The primary outcome measure, the NRS pain scores, did not differ between the groups at either baseline $(\mathrm{P}=0.886)$ or at 3 weeks $(P=0.279)$. Although the median difference between the baseline NRS pain scores and those at 3 weeks in the pregabalin group was only $0.75(\mathrm{P}=0.375)$, the median difference in the placebo group was $2(\mathrm{P}=0.047)$, which was not significant after adjusting the criterion for the rejection of 
the null hypothesis. The ODI score did not differ between the groups at either baseline $(\mathrm{P}=0.117)$ or at 3 weeks $(\mathrm{P}=$ 0.139). The median difference between the baseline ODI score and that at 3 weeks in the pregabalin group was 10.0 $(\mathrm{P}=0.160)$, while the median difference in the placebo group was $12.5(\mathrm{P}=0.039)$, which was not significant after adjusting the criterion for the rejection of the null hypothesis. The PGIC did not differ between the groups ( $\mathrm{P}=0.282$ ).

The NRS, ODI, and PGIC scores of each patient in the two study groups, prior to and after the 3-week treatment, along with the change in the individual scores are presented in Table 3 and Table 4 . Using the pre-established criteria (12-14), only 2 of the 10 patients $(20 \%)$ treated with pregabalin (Table 3 ) and 4 of the 9 patients (44\%) who took placebo had successful reduction in their pain and disability scores and were satisfied with their treatment. Even though twice as many patients in the placebo group had successful reduction in their pain and disability scores and reported satisfaction with their treatment, these differences were not statistically significant ( $\mathrm{P}=0.350$ by the Fisher exact probability test).

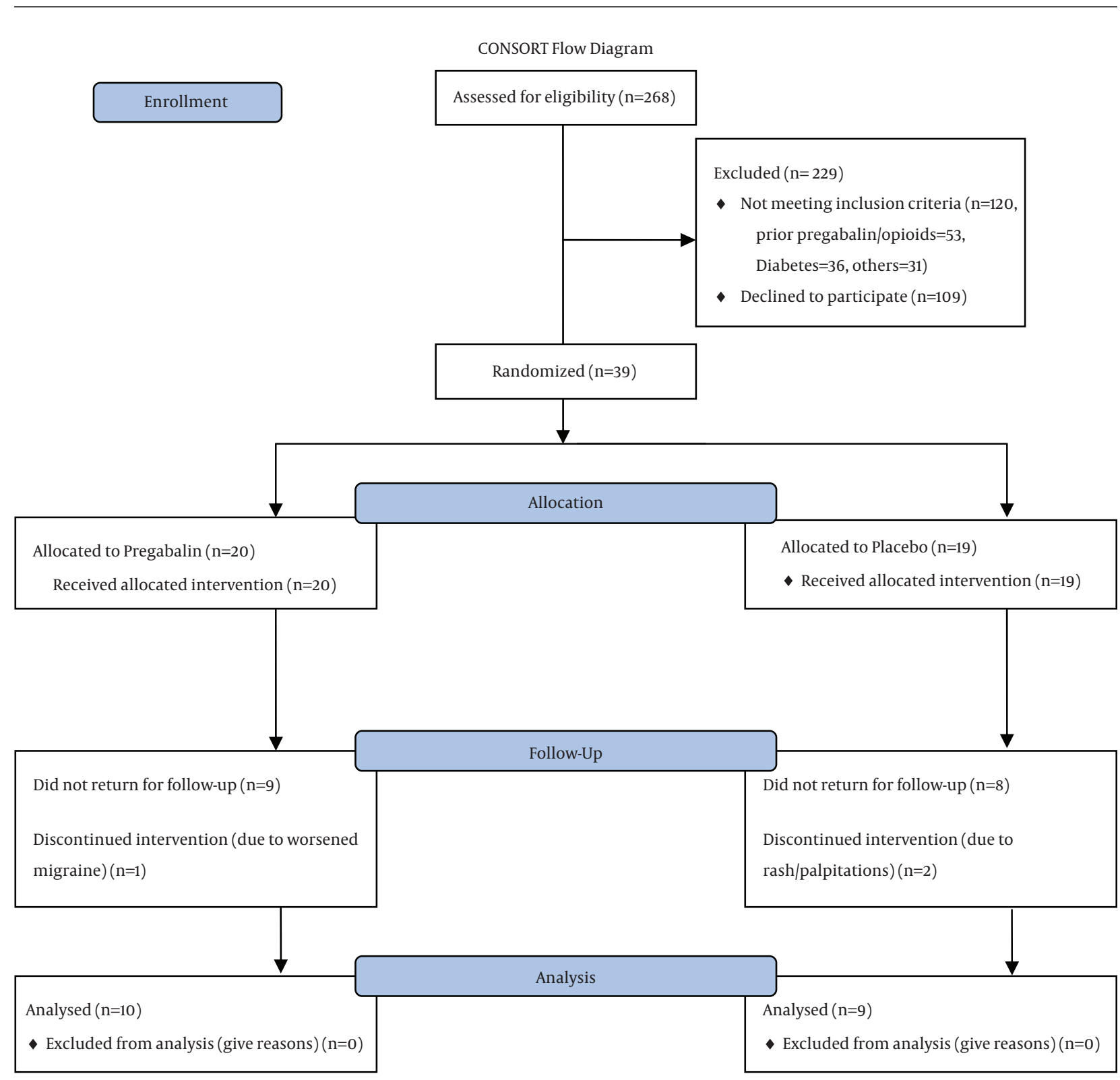

Figure 1. Consort Flow Diagram of the Eligible Patients, Randomization, Treatment Allocation, Follow-up, and Data Analysis 
Table 1. Patient Baseline Characteristics a,b,c

\begin{tabular}{|c|c|c|c|c|}
\hline & $\begin{array}{l}\text { Placebo Group } \\
\text { Completed Trial }\end{array}$ & $\begin{array}{l}\text { Pregabalin Group } \\
\text { Completed Trial }\end{array}$ & $\begin{array}{l}\text { Placebo Group } \\
\text { Withdrew }\end{array}$ & $\begin{array}{l}\text { Pregabalin Group } \\
\text { Withdrew }\end{array}$ \\
\hline Sample Size, $n$ & 9 & 10 & 10 & 10 \\
\hline Age, y & $42 \pm 13$ & $44 \pm 8$ & $46 \pm 14$ & $51 \pm 11$ \\
\hline Female & $4(44)$ & $6(60)$ & $4(40)$ & $5(50)$ \\
\hline Lumbar Pain & $5(56)$ & $8(80)$ & $8(80)$ & $8(80)$ \\
\hline Prior Surgery & $1(11)$ & $1(10)$ & $2(20)$ & $3(30)$ \\
\hline \multicolumn{5}{|c|}{ Numeric Rating Scale Pain Score } \\
\hline Baseline & $6(3-8)$ & $6.5(2-9)$ & $5(2-8)$ & $6.5(2-8)$ \\
\hline \multicolumn{5}{|c|}{ Oswestry Disability Index (\%) } \\
\hline Baseline & $40(16-72)$ & $52.5(26-64)$ & $49(30-70)$ & $50(22-66)$ \\
\hline \multicolumn{5}{|c|}{$\begin{array}{l}\text { a Data are as mean } \pm \text { standard deviation; median (range), or No. }(\%) \text {. } \\
\text { b Numeric rating scale pain score was evaluated on an 11-point verbal rating scale ( } 0=\text { no pain and } 10=\text { worst pain imaginable). } \\
\text { c Oswestry disability index generated percent disability (total score } / 50 \times 100 \text { ): } 0 \% \text { to } 20 \% \text { indicated minimal disability (the patient could cope with } \\
\text { most living activities); } 21 \% \text { - } 40 \% \text { indicated moderate disability (the patient had difficulty sitting, lifting, and standing and, therefore, had limitations } \\
\text { with travel, social life, and some vocational activities); } 41 \%-60 \% \text { indicated severe disability which affected the activities of daily living; } 61 \%-80 \% \text { denoted } \\
\text { crippled patients (this level of disability impinged on all aspects of the patient's life); and } 81 \%-100 \% \text { indicated that the patient was bed-bound. }\end{array}$} \\
\hline
\end{tabular}

Table 2. Response to Treatment Measured in the Domains of Pain, Disability, and Satisfaction with Treatment ${ }^{\text {a,b,c,d }}$

\begin{tabular}{|c|c|c|c|c|}
\hline & Placebo & Pregabalin & Median Difference $(99 \% \mathrm{CI}) \mathrm{e}$ & P Value $^{\mathrm{e}}$ \\
\hline Sample Size, $\mathbf{n}$ & 9 & 10 & & \\
\hline \multicolumn{5}{|c|}{ Numeric Rating Scale Pain Score } \\
\hline Baseline & $6(3-8)$ & $6.5(2-9)$ & $0(-3-2)$ & 0.886 \\
\hline 3 weeks & $3(0-8)$ & $6(1-9)$ & $-2(-6-3)$ & 0.279 \\
\hline Median Difference $(99 \% \mathrm{CI})^{\mathrm{f}}$ & $2(-0.5-5)$ & $0.75(-1-2.75)$ & & \\
\hline $\mathbf{P}^{\mathbf{f}}$ & 0.047 & 0.375 & & \\
\hline
\end{tabular}

Oswestry Disability Index (\%)

\begin{tabular}{lcccc}
\hline Baseline & $40(16-72)$ & $52.5(26-64)$ & $-11.5(-34-14)$ & 0.117 \\
\hline 3 weeks & $20(2-60)$ & $41(8-64)$ & $-16(-42-16)$ & 0.139 \\
\hline Median Difference $(\mathbf{9 9} \% \mathbf{C I}) \mathbf{f}$ & $12.5(-5-26)$ & $10(-11-27)$ & & \\
\hline $\mathbf{P}^{\mathbf{f}}$ & 0.039 & 0.160 & & 0.282 \\
\hline Patient's Global Impression of Change & & & $-1(-2-1)$ & \\
\hline 3 weeks & $3(1-4)$ & $3.5(1-5)$ & & \\
\hline
\end{tabular}

\footnotetext{
a Data are presented as median (range).

b Numeric rating scale pain score was evaluated on an 11-point verbal rating scale $(0=$ no pain and $10=$ worst pain imaginable).

c Oswestry disability index generated percent disability (total score $/ 50 \times 100$ ): $0 \%$ to $20 \%$ indicated minimal disability (the patient could cope with most living activities); $21 \%$ - 40\% indicated moderate disability (the patient had difficulty sitting, lifting, and standing and, therefore, had limitations with travel, social life, and some vocational activities); $41 \%$ - 60\% indicated severe disability which affected the activities of daily living; $61 \%-80 \%$ denoted crippled patients (this level of disability impinged on all aspects of the patient's life); and $81 \%-100 \%$ indicated that the patient was bed-bound.

d Patient's Global Impression of Change indicated the patient's overall impression of change over the course of the study and ranged from 1 to 7 , indicating very much improved (1), much improved (2), minimally improved (3), no change (4), minimally worse (5), much worse (6), and very much worse (7).

e Median differences between the groups and their $99 \%$ confidence intervals and the P values for the group comparisons by the Mann-Whitney U Test are provided.

$\mathrm{f}_{\mathrm{f}}$ Median differences within the groups and their $99 \%$ confidence intervals and the P values for the group comparisons by the Wilcoxon signed-ranks test are provided.
} 
Table 3. Individual Results of the Patients in the Pregabalin Group

\begin{tabular}{|c|c|c|c|c|c|c|c|c|c|c|c|}
\hline \# & Age & Sex & BL-NRS & 3wk-NRS & $\Delta \mathrm{NRS}$ & BL-\%ODI & 3wk-\%ODI & $\Delta \%$ ODI & 3wk-PGIC & Interpretation & $\begin{array}{c}\text { Overall } \\
\text { Result }\end{array}$ \\
\hline $\mathbf{1}$ & 44 & male & 4 & 1 & 3 & 46 & 8 & 38 & 1 & $\begin{array}{l}\text { Significant improve- } \\
\text { ment in pain, dis- } \\
\text { ability, and patient } \\
\text { satisfaction }\end{array}$ & Effective \\
\hline 2 & 37 & male & 7.5 & 5 & 2.5 & 56 & 38 & 18 & 2 & $\begin{array}{l}\text { Significant improve- } \\
\text { ment in pain, dis- } \\
\text { ability, and patient } \\
\text { satisfaction }\end{array}$ & Effective \\
\hline 3 & 49 & female & 2 & 3 & -1 & 26 & 34 & -8 & 4 & $\begin{array}{l}\text { No significant } \\
\text { change in pain, } \\
\text { disability, or patient } \\
\text { satisfaction }\end{array}$ & Ineffective \\
\hline 4 & 27 & male & 6 & 7 & -1 & 54 & 48 & 6 & 3 & $\begin{array}{l}\text { No significant } \\
\text { change in pain, } \\
\text { disability, or patient } \\
\text { satisfaction }\end{array}$ & Ineffective \\
\hline 5 & 45 & female & 7 & 7 & 0 & 64 & 56 & 8 & 5 & $\begin{array}{c}\text { No significant } \\
\text { change in pain, } \\
\text { disability, or patient } \\
\text { satisfaction }\end{array}$ & Ineffective \\
\hline 6 & 39 & female & 7 & 7 & 0 & 50 & 64 & -14 & 5 & $\begin{array}{c}\text { No significant } \\
\text { change in pain or } \\
\text { patient satisfaction } \\
\text { but worsened dis- } \\
\text { ability }\end{array}$ & Inconclusive \\
\hline 7 & 56 & male & 5 & 4 & 1 & 58 & 44 & 14 & 3 & $\begin{array}{l}\text { No significant } \\
\text { change in pain or } \\
\text { patient satisfaction } \\
\text { but significantly } \\
\text { improved disability }\end{array}$ & Inconclusive \\
\hline
\end{tabular}

\begin{tabular}{|c|c|c|c|c|c|c|c|c|c|c|c|}
\hline 8 & 52 & female & 9 & 9 & 0 & 62 & 38 & 24 & 4 & $\begin{array}{c}\text { No significant } \\
\text { improvement in } \\
\text { pain or patient } \\
\text { satisfaction but sig- } \\
\text { nificantly improved } \\
\text { disability }\end{array}$ & Inconclusive \\
\hline 9 & 45 & female & 6 & 7 & -1 & 51 & 62 & -11 & 3 & $\begin{array}{c}\text { No significant } \\
\text { change in pain or } \\
\text { patient satisfaction } \\
\text { but worsened dis- } \\
\text { ability }\end{array}$ & Inconclusive \\
\hline 10 & 43 & female & 7 & 4 & 3 & 34 & 18 & 16 & 4 & $\begin{array}{l}\text { Significantly im- } \\
\text { proved pain and dis- } \\
\text { ability scores but no } \\
\text { change in patient } \\
\text { satisfaction }\end{array}$ & Inconclusive \\
\hline
\end{tabular}




\begin{tabular}{|c|c|c|c|c|c|c|c|c|c|c|c|}
\hline \# & Age & Sex & BL-NRS & 3wk-NRS & $\Delta \mathrm{NRS}$ & BL-\%ODI & 3wk-\%ODI & $\Delta \%$ ODI & 3wk-PGIC & Interpretation & $\begin{array}{c}\text { Overall } \\
\text { Result }\end{array}$ \\
\hline $\mathbf{1}$ & 26 & female & 8 & 3 & 5 & 58 & 42 & 16 & 2 & $\begin{array}{l}\text { Significant improve- } \\
\text { ment in pain, dis- } \\
\text { ability, and patient } \\
\text { satisfaction }\end{array}$ & Effective \\
\hline 2 & 38 & male & 4 & 1 & 3 & 24 & 4 & 20 & 2 & $\begin{array}{l}\text { Significant improve- } \\
\text { ment in pain, dis- } \\
\text { ability, and patient } \\
\text { satisfaction }\end{array}$ & Effective \\
\hline 3 & 62 & male & 6 & 1 & 5 & 40 & 18 & 22 & 2 & $\begin{array}{l}\text { Significant improve- } \\
\text { ment in pain, dis- } \\
\text { ability, and patient } \\
\text { satisfaction }\end{array}$ & Effective \\
\hline 4 & 47 & male & 4 & 0 & 4 & 32 & 2 & 30 & 1 & $\begin{array}{l}\text { Significant improve- } \\
\text { ment in pain, dis- } \\
\text { ability, and patient } \\
\text { satisfaction }\end{array}$ & Effective \\
\hline 5 & 23 & male & 8 & 8 & 0 & 48 & 54 & -6 & 4 & $\begin{array}{l}\text { No significant } \\
\text { change in pain, } \\
\text { disability, or patient } \\
\text { satisfaction }\end{array}$ & Ineffective \\
\hline 6 & 39 & female & 7 & 8 & -1 & 19 & 16 & 3 & 3 & $\begin{array}{l}\text { No significant } \\
\text { change in pain, } \\
\text { disability, or patient } \\
\text { satisfaction }\end{array}$ & Ineffective \\
\hline 7 & 60 & female & 3 & 2 & 1 & 16 & 20 & -4 & 4 & $\begin{array}{l}\text { No significant } \\
\text { change in pain, } \\
\text { disability or patient } \\
\text { satisfaction }\end{array}$ & Ineffective \\
\hline 8 & 46 & male & 7 & 7 & 0 & 72 & 60 & 12 & 3 & $\begin{array}{l}\text { No significant } \\
\text { improvement in pain } \\
\text { or patient satisfac- } \\
\text { tion but significantly } \\
\text { improved disability }\end{array}$ & Inconclusive \\
\hline 9 & 37 & female & 6 & 4 & 2 & 44 & 28 & 16 & 4 & $\begin{array}{l}\text { Significant improve- } \\
\text { ment in pain and } \\
\text { disability scores but } \\
\text { no change in patient } \\
\text { perception }\end{array}$ & Inconclusive \\
\hline
\end{tabular}

\section{Discussion}

The efficacy of pregabalin has been demonstrated in multiple randomized, controlled trials for a number of neuropathic pain conditions such as post-herpetic neuralgia $(16,17)$, diabetic neuropathy $(18,19)$, fibromyalgia (20), and spinal cord injury pain (15). We encountered two previous studies of pregabalin use in patients with $\mathrm{RP}(21,22)$. While one such trial reported inconclusive results (21), the other reported the efficacy of pregabalin in patients with cervical radiculopathy (22). The latter trial, however, cited significant study limitations and recommended further evaluation of pregabalin in patients with RP by a well-designed study.

Our study was supported by a departmental research award and, as a result, the financial resources available to conduct this study were limited. Therefore, to maintain a relatively small sample size that would still demonstrate a statistical difference between groups, we targeted only patients that would have the most robust benefit from pregabalin treatment. Consequently, our study eligibility criteria were strict. Based on the efficacy of pregabalin for neuropathic pain and the possible neuropathic nature of RP in low back and neck pain patients, we attempted to recruit only patients with RP. As no objective tests are routinely done to clearly diagnose RP, we limited our study to patients with typical radicular symptoms with spinal etiology most likely to cause RP, viz. patients with herniated discs, 
spinal stenosis, or failed back surgery syndrome. To avoid false-positive results, we excluded patients with other neuropathic pain conditions. To reduce false-negative results, we excluded patients who were more likely on average to continue to report pain despite treatment benefit, namely depressed patients, patients with opioid or other drug tolerance/addiction, and patients who had disability or who had filed for workmen's compensation. Patients taking powerful narcotics such as morphine, oxycodone, hydromorphone, oxymorphone, and transdermal fentanyl were excluded from the study. We only included patients taking mild analgesics such as nonsteroidal anti-inflammatory drugs, acetaminophen, and tramadol so that any potential benefit of pregabalin was not obscured by strong analgesics. Moreover, as the majority of the patients presented to our practice for epidural steroid injections, we only included patients who had received at least two epidural injections within the past 6 months. Even though the strict criteria adopted in this study may have excluded patients with low back and neck pain who could have benefited otherwise from treatment with pregabalin, we believe the patient population targeted in this study, i.e. patients who are intolerant to opioids with RP that is unresponsive to epidural steroid injections, represents the segment of low back and neck pain patients who had the potential to benefit the most from pregabalin.

Our study population, therefore, comprised a small, fairly homogenous target group of patients with chronic lumbar and cervical RP who were randomized to receive a short course of pregabalin or placebo. The results of our study showed no statistically significant difference in the outcomes with regard to an overall improvement in pain, disability, or patient satisfaction between the two groups. Although the differences in the outcomes between the groups were not statistically significant, the results were notable for other findings. A clinically significant (12) decrease in the median pain scores was encountered only in the placebo group: a difference of 2 points for the placebo group compared to a difference of 0.75 points for the pregabalin group. Treatment with both placebo and pregabalin produced at least a 10\% decrease in disability, which is considered a significant change based on the aforementioned criteria (13). Furthermore, neither placebo nor pregabalin treatment achieved a median score of 1 , 2,5 , or 6 on the PGIC, which would have been considered a substantial change (14). Due to the small study size, we analyzed the outcome scores of each individual patient (Tables 3 and 4) and determined the success or failure of the treatment based on the pre-established criteria (1214). Using these standards, twice as many patients in the placebo group had successful reduction in their pain and disability and were satisfied with their treatment.

The results of our study, therefore, do not suggest that pregabalin is more efficacious than placebo for the treatment of cervical and lumbar RP in this target group of patients. Even though the treatment with pregabalin was of a short duration and the patients were followed up for only a brief period of time, any trend toward improvement in this group of patients would have been meaningful.

Our study had several limitations, including a small sample size and a high dropout rate. Most of the patients in this study were recruited between 2009 and 2010 and only 1 patient was recruited between October 13th, 2011 and August 9th, 2012. Considering the high dropout rate, we attempted to recruit additional patients over the intended target of 38. However, this effort was abandoned due to budgetary constraints and the extremely slow recruitment rate, especially in the later stages of the study. A probable reason for the slow recruitment and, ultimately, the small sample size was the stringent selection criteria employed. Slow recruitment, especially in the later stages of the study, may also have been due to the increasing number of patients already being treated with pregabalin or gabapentin. Although follow-up data were not available for 20 of the 39 patients recruited in the study, the uniform dropout rate (10 patients in each group) with similar demographic characteristics probably did not affect the overall results of this study.

Despite its limitations, this study is important for several reasons. First, despite its small size, the study results were not indicative of obvious benefit of pregabalin over placebo. These results do not discredit but should discourage the frequent prescription of pregabalin to patients with various low back and neck pain syndromes. Secondly, we were able to randomly assign patients with $\mathrm{RP}$ to placebo or pregabalin treatment before the use of pregabalin and gabapentin had become common. The now increasingly common prescription of these medications by primary care providers may preclude a largescale study in the future. Thirdly, it is hoped that the results of this study will lead to a larger, well-controlled, randomized clinical trial of the efficacy of pregabalin in the treatment of RP before such use becomes permanently engrained among pain physicians.

Due to the non-prodigious results of this study, there remains a persistent need to appraise the exorbitant practice of pregabalin use in a large proportion of patients with low back and neck pain. Based on the difficulties experienced with patient recruitment and retention in this study, the following recommendations can be made for a larger wellfunded future clinical trial:1) include all patients with radicular symptoms irrespective of the etiology; 2) include patients already being treated with pregabalin, gabapentin, and opioids; 4) provide treatment for a longer duration, 3 months, to appropriately gauge any potential benefit, especially for patients already taking this class of drugs, and keep record of the narcotics used; and 5) exclude only patients with documented peripheral neuropathy.

\section{Authors' Contributions}

Khalid Mehmood Malik: Main idea and manuscript preparation. Ariana M. Nelson: Data analysis and manuscript preparation. Michael J. Avram: Statistics. Sabrina 
Lee Robak: Data collection. Honorio T. Benzon: Data analysis and manuscript preparation.

\section{Funding/Support}

Melissa Fragen grant, department of anesthesiology, Northwestern university, Chicago $\$ 5000$.

\section{References}

1. Wiffen PJ, Derry S, Moore RA, Aldington D, Cole P, Rice AS, et al. Antiepileptic drugs for neuropathic pain and fibromyalgia an overview of Cochrane reviews. Cochrane Database Syst Rev. 2013;11:CD010567.

2. Lyrica $®$ package insert. Parke-Davis Division of Pfizer Inc.New York, NY 10017 USA: 2013.

3. Merskey H, Bogduk N. Classification of chronic pain: description of chronic pain syndromes and definitions of pain terms. 2th ed. Seattle, WA: IASP Press; 1994.

4. Backonja MM. Defining neuropathic pain. Anesth Analg. 2003;97(3):785-90.

5. Dworkin RH, Backonja M, Rowbotham MC, Allen RR, Argoff CR, Bennett GJ, et al. Advances in neuropathic pain: diagnosis, mechanisms, and treatment recommendations. Arch Neurol. 2003;60(11):1524-34.

6. Stafford MA, Peng P, Hill DA. Sciatica: a review of history, epidemiology, pathogenesis, and the role of epidural steroid injection in management. BrJAnaesth. 2007;99(4):461-73.

7. Wall PD, Devor M. Sensory afferent impulses originate from dorsal root ganglia as well as from the periphery in normal and nerve injured rats. Pain.1983;17(4):321-39.

8. Howe JF, Loeser JD, Calvin WH. Mechanosensitivity of dorsal root ganglia and chronically injured axons: a physiological basis for the radicular pain of nerve root compression. Pain. 1977;3(1):25-41.

9. Deyo RA, Tsui-Wu YJ. Descriptive epidemiology of low-back pain and its related medical care in the United States. Spine (Phila Pa 1976). 1987;12(3):264-8.

10. Frymoyer JW, Cats-Baril WL. An overview of the incidences and costs of low back pain. Orthop Clin North Am. 1991;22(2):263-71.

11. Svensson HO, Andersson GB. Low-back pain in 40- to 47 -year-old men: work history and work environment factors. Spine (Phila Pa 1976). 1983;8(3):272-6

12. Farrar JT, Young JJ, LaMoreaux L, Werth JL, Poole RM. Clinical importance of changes in chronic pain intensity measured on an 11-point numerical pain rating scale. Pain. 2001;94(2):149-58.

13. Fairbank JC, Couper J, Davies JB, O'Brien JP. The Oswestry low back pain disability questionnaire. Physiotherapy. 1980;66(8):271-3.

14. Hurst $\mathrm{H}$, Bolton J. Assessing the clinical significance of change scores recorded on subjective outcome measures.J Manipulative Physiol Ther. 2004;27(1):26-35.

15. Siddall PJ, Cousins MJ, Otte A, Griesing T, Chambers R, Murphy TK. Pregabalin in central neuropathic pain associated with spinal cord injury: a placebo-controlled trial. Neurology. 2006;67(10):1792-800.

16. Sabatowski R, Galvez R, Cherry DA, Jacquot F, Vincent E, Maisonobe $P$, et al. Pregabalin reduces pain and improves sleep and mood disturbances in patients with post-herpetic neuralgia: results of a randomised, placebo-controlled clinical trial. Pain. 2004;109(1-2):26-35.

17. van Seventer R, Feister HA, Young JJ, Stoker M, Versavel M, Rigaudy L. Efficacy and tolerability of twice-daily pregabalin for treating pain and related sleep interference in postherpetic neuralgia: a 13-week, randomized trial. Curr Med Res Opin. 2006;22(2):375-84.

18. Lesser H, Sharma U, LaMoreaux L, Poole RM. Pregabalin relieves symptoms of painful diabetic neuropathy: a randomized controlled trial. Neurology. 2004;63(11):2104-10.

19. Richter RW, Portenoy R, Sharma U, Lamoreaux L, Bockbrader H, Knapp LE. Relief of painful diabetic peripheral neuropathy with pregabalin: a randomized, placebo-controlled trial. J Pain. 2005;6(4):253-60.

20. Arnold LM, Russell IJ, Diri EW, Duan WR, Young JJ, Sharma U, et al. A 14-week, randomized, double-blinded, placebo-controlled monotherapy trial of pregabalin in patients with fibromyalgia. JPain. 2008;9(9):792-805.

21. Baron R, Freynhagen R, Tolle TR, Cloutier C, Leon T, Murphy TK, et al. The efficacy and safety of pregabalin in the treatment of neuropathic pain associated with chronic lumbosacral radiculopathy. Pain. 2010;150(3):420-7.

22. Lo YL, Cheong PW, George JM, Tan SB, Yue WM, Guo CM, et al. Pregabalin and Radicular Pain Study (PARPS) for Cervical Spondylosis in a Multiracial Asian Population. J Clin Med Res. 2014;6(1):66-71. 